\title{
Cosmetic effects of skin-crease camouflage incision versus longitudinal incision following carotid endarterectomy
}

\author{
Arkadiusz Kazimierczak, Anita Rybicka, Pawel Rynio, Piotr Gutowski, Ireneusz Wiernicki \\ Department of Vascular Surgery, Pomeranian Medical University, Szczecin, Poland
}

Videosurgery Miniinv 2018; 13 (1): 102-110

DOI: https://doi.org/10.5114/wiitm.2018.72646

\begin{abstract}
Introduction: Despite the increasing use of carotid angioplasty and stenting (CAS), carotid endarterectomy (CEA) nonetheless remains a more medically beneficial method of treatment for carotid artery stenosis. Therefore, one possibility for progress within this procedure may be to use minimally invasive carotid surgery, especially when the scar is in plain sight: the use of the natural wrinkles (skin crease) as a camouflage of the skin incision provides significant cosmetic improvements.

Aim: To compare the cosmetic effects of classic and trans-wrinkle CEA. To assess the distance between the carotid artery bifurcation (CAB) and the skin-crease incision whilst attempting CEA.

Material and methods: It was a randomized prospective study with two groups: patients undergoing classic surgery (control group; $n=100$ ) and skin-crease trans-wrinkle camouflaged CEA (study group; $n=100$ ). Follow-up was at 2 months and 1 year.

Results: The medical results of the treatment were similar in both groups. The cumulative count of strokes and myocardial infarctions was $0.5 \%$ within 30 days, and after one year 3.5\% (and 5.5\% including cases of death). The superiority of the transverse crease being hidden compared to the conventional longitudinal technique was proven in the Patient and Observer Scar Assessment Scale (POSAS) score, respectively $11.4 \pm 1.0$ vs. $14.1 \pm 3.4(p=0.0001)$ after 2 months and $13.5 \pm 2.8$ vs. $14.1 \pm 3.4(p=0.039)$ after a year.

Conclusions: Trans-wrinkle incision gives better cosmetic results, can be safely performed in most cases, and offers a comfortable approach during CEA.
\end{abstract}

Key words: carotid endarterectomy, skin-crease incision, randomized control study, scar assessment.

\section{Introduction}

Carotid endarterectomy (CEA) remains a preferred medical procedure and, as a consequence, it is possible that progress can be made via minor invasive carotid surgery in order to reduce the resulting scar which is invariably visible. The results of the first minimally invasive CEA were initially published in 2005 [1]. The idea of skin-crease camouflage (transversal incision) has been known for more than 20 years and remains popular in some centres.
Furthermore, although the safety of this minimally invasive technique is widely acknowledged, the transverse skin-crease incision still remains a less popular choice $[2,3]$. This is despite the fact that comparisons concerning the cosmetic effects between minimally invasive methods and the conventional longitudinal approach are readily available [2-5]. However, in the past decade transversal, skincrease camouflaged solutions have been somewhat overlooked as this method is seen as more difficult [5]. This might be due to the fact that no randomized

\section{Address for correspondence}

Pawel Rynio MD, Department of Vascular Surgery, Pomeranian Medical University, 80/33 Powstańców Wlkp. St, 70-110 Szczecin, Poland, phone: +48 792456 045, e-mail: ryniopawel@gmail.com 
control trials have been conducted to investigate its use. Moreover, using skin wrinkles as markers of carotid artery bifurcation and as a replacement for ultrasound mapping, as well as the camouflage of the skin incision, provides an interesting alternative in CEA [2, 5]. As a result, we conducted a small randomized prospective trial to compare the cosmetic results of conventional longitudinal and transversal (skin-crease, trans-wrinkle) attempts in CEA.

\section{Aim}

A comparison of the cosmetic effects between conventional and skin-crease camouflaged CEA during 1-year follow-up. To assess the range of distance between carotid artery bifurcation (CAB) and the skin-crease incision whilst attempting CEA.

\section{Material and methods}

Consecutive patients who qualified for CEA between 2013 and 2014 at the Department of Vascular Surgery at the Pomeranian Medical University in Szczecin, Poland, were initially considered (262 cases). A written consent form signed by the patient, developed from a simple preference question ("Am I concerned about the cosmetic effects of the operation? Yes or No), was taken prior to the randomization. Inclusion criteria were: internal carotid artery (ICA) stenosis > 50\% for symptomatic cases, asymptomatic stenosis $>70 \%$ for male, and $>80 \%$ for female patients. Exclusion criteria: qualification for carotid angioplasty and stenting (CAS) due to high cardiac risk, poor functional status with a score < 60 on the Karnofsky/Lansky performance scale, the need for pharmacological optimization before surgery and the withdrawal of written consent [6-8]. The randomization was performed by allocation during the process of minimization (using sealed opaque envelopes) $[9,10]$. The prognostic variables considered in the randomized group were gender, patients concerned about cosmetic effects, as well as surgery preferences (for and against transverse incision) to avoid preferential self selection. The surgeons were told the incision type that would be made on the day of surgery. However, in 7 cases, patients were moved to the other group on the decision of a surgeon. Nevertheless, 200 patients were successfully randomized to two groups (with no significant differences in prognostic variables allocation). See flow Figure 1. The control group un- derwent the classic surgical CEA method with a skin incision along the anterior border of the sternocleidomastoid muscle, also known as an oblique or longitudinal incision. The study group underwent skincrease trans-wrinkle camouflaged incision, known as a transverse incision. All the patients received antiplatelet therapy (acetylsalicylic acid 75-100 mg) and a statin prior to, as well as after, surgery.

A cervical plexus blockade (deep and superficial) was performed by an anaesthetist in all cases, supported by local analgesia during surgery when necessary. In the study group, "access skin wrinkle" (ASW) was defined as a skin crease approximately $4 \mathrm{~cm}$ below the mandibular angle (with the patient's head in a sniffing position) and marked before analgesia (Photos $1 \mathrm{~A}, \mathrm{~B}$ ). In the cases of absence of any visible wrinkle, a choice was made while bending the neck to reveal Langer's lines [11]. In the control group the typical incision running along the anterior border of the sternocleidomastoid muscle was used. Heparin was given intravenously (range: 30-50 mg) before clamping. Neuromonitoring was achieved by checking patient speech. The shunt technique (14\%) was used if the level of consciousness was depressed during the 2-minute clamping test of the carotid artery $[12,13]$. The surgical method of removing plaque depended on the preferences of the surgical team. In the study group, the distance between carotid artery bifurcation and the mandibular angle was measured before closing, using a thread extended from the mandibular angle down to the CAB (an appropriate thread length was then cut and measured after surgery with a ruler) and recorded in the files of each patient (Photo 1 C, D). Distance measurement was carried out on the most comfortable neck position (for the surgeon) and was chosen during surgery (Photo $1 \mathrm{~A}$ ).

All patients received routine post-operative deep vein thrombosis prevention (the dose of low-molecular-weight heparin was dependent on body weight). Patients were discharged the second day after surgery on 75-100 mg acetylsalicylic acid. Complications, e.g. local neurological (neural palsy), stroke/ transient ischemic attack (TIA), acute coronary syndrome (ACS) and death, were logged and counted up to 30 days and 12 months after surgery. The POSAS scale was used to assess the cosmetic effect at the $2^{\text {nd }}$ and the $12^{\text {th }}$ month after surgery by an independent medical professional (a surgical nurse) in an outpatient clinic. The POSAS scale consists of 


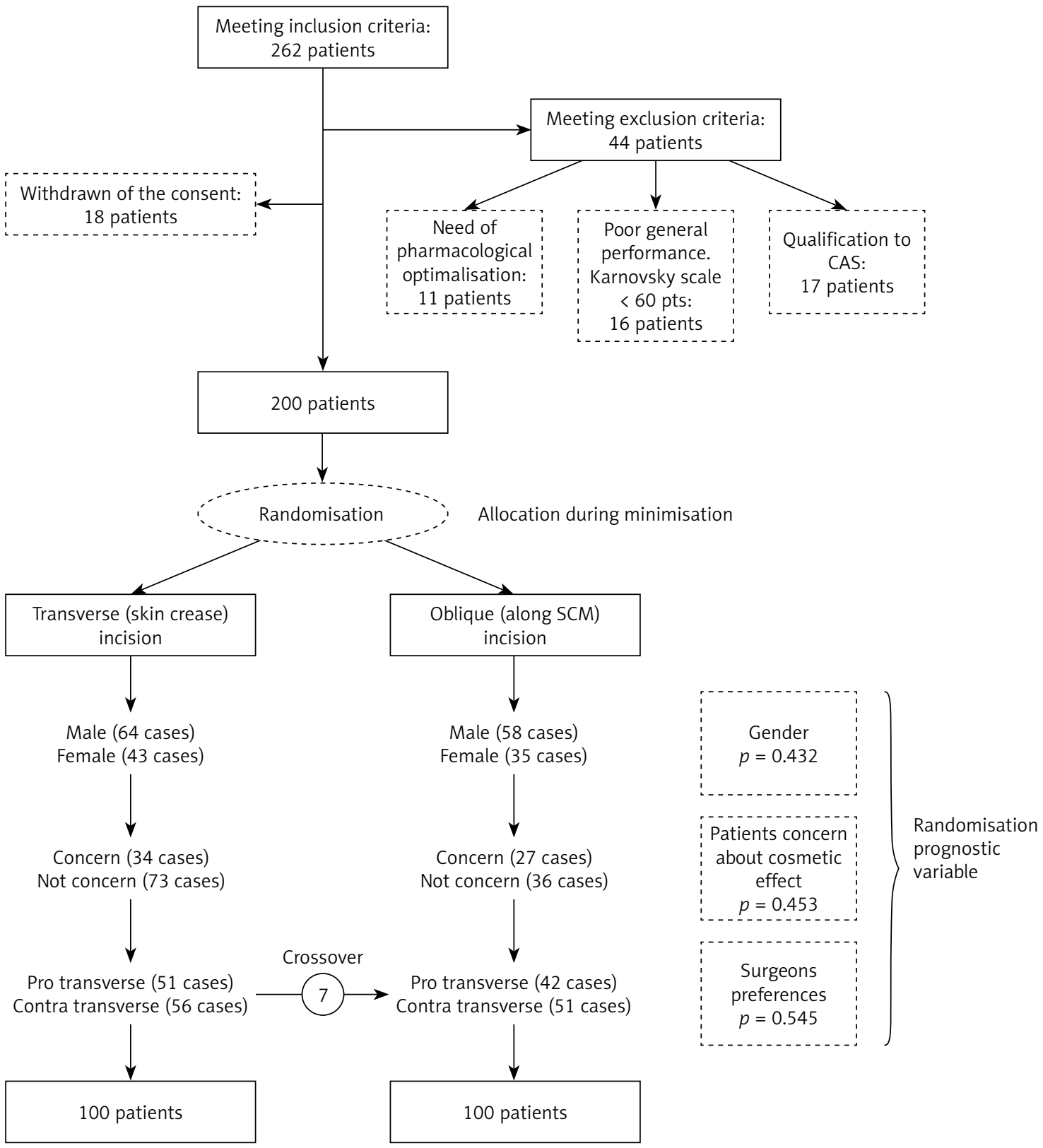

Figure 1. Flow of patients in groups

two numeric scales: a Patient Scar Assessment Scale (carried out by the patient), and the Observer Scar Assessment Scale (filled out by an observer). The Patient scale contains six items (scar colour, pliability, thickness, relief, itching and pain), and the observer scale contains five items (scar vascularization, pigmentation, pliability, thickness and relief). All items within the two scales were scored numerically. The patient scale summarizes the scores of each of the six items (range: 6 to 60), whilst the observer scale summarizes each of the five items (range: 5 to 50 ).
The lowest scores, 6 and 5, respectively, reflect normal skin [14] (Appendix 1). A photographic example 2 months after surgery is shown in Photo 2.

The study was conducted in accordance with the Guidelines for Good Clinical Practice and the Helsinki Declaration, and was approved by the Ethics Committee (14/KB/V/2013, OIL, Szczecin) and registered at the Pomeranian Medical University (Szczecin, Poland) as "Patient Comfort and early Results after Carotid Endarterectomy by Transversal versus Classic Surgical procedures" (CORRECTA Trial; WL-103- 

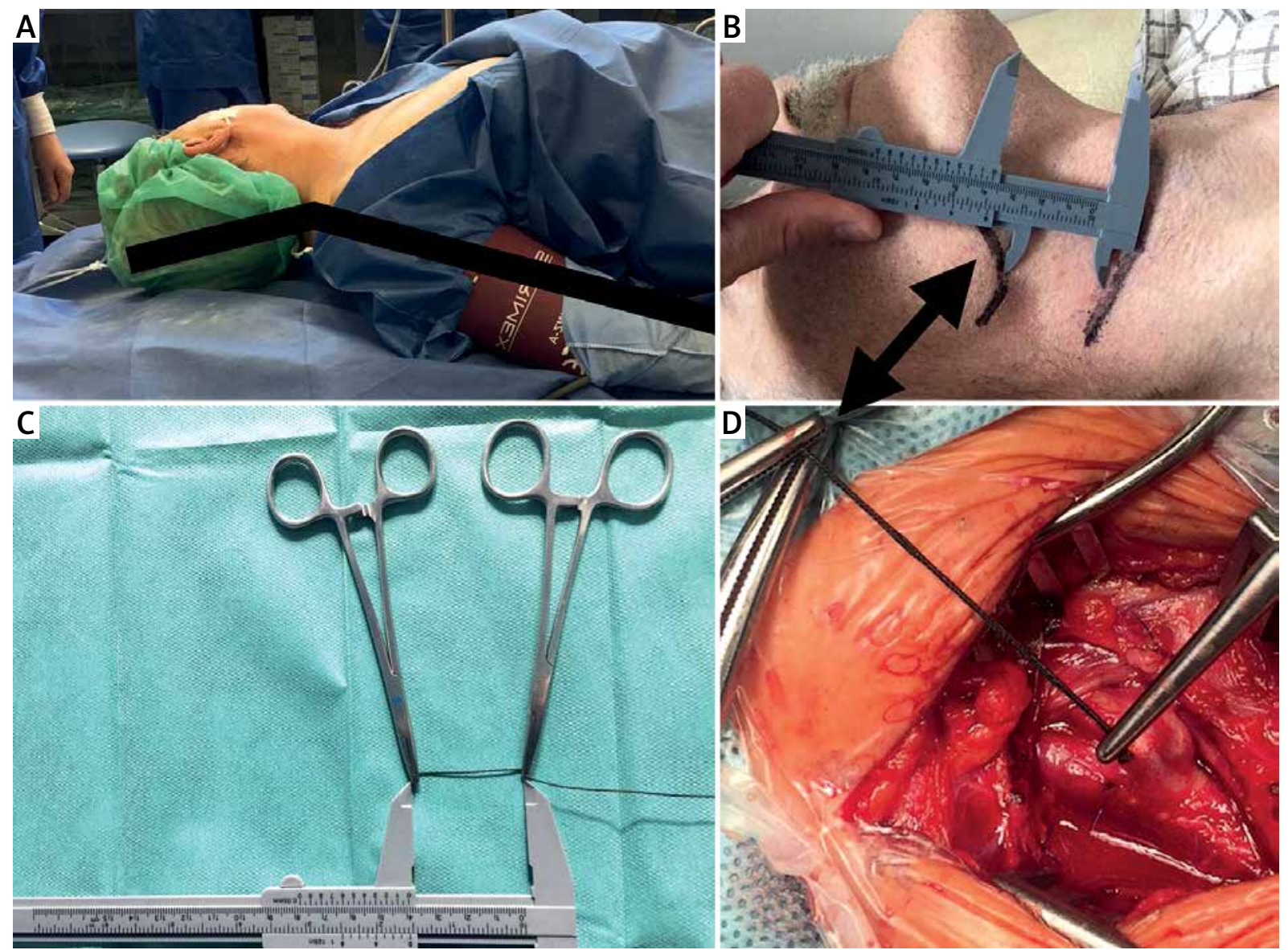

Photo 1. Patient position and measurements. A - Patient position during surgery and distance measurement, B - Measurement of the distance between carotid artery bifurcation and the mandibular angle. C - Measurement of thread length after surgery. D - Thread extended from the mandibular angle down to the $C A B$

01/S/12). The trial was designed in accordance with the CONSORT statement [15].

\section{Statistical analysis}

Commercial statistics software was used (Statistica; StatSoft, Inc. USA). Distribution was checked with the Shapiro-Wilk test. A comparison of quantitative variables was performed with $t$ tests (Mann-Whitney $U$ test, if not normally distributed). Qualitative variable comparisons were performed using Fisher's exact test. Differences were defined as significant if $p<0.05$.

\section{Results}

\section{Patients}

The demographics and baseline characteristics of the study population are given in Table I.

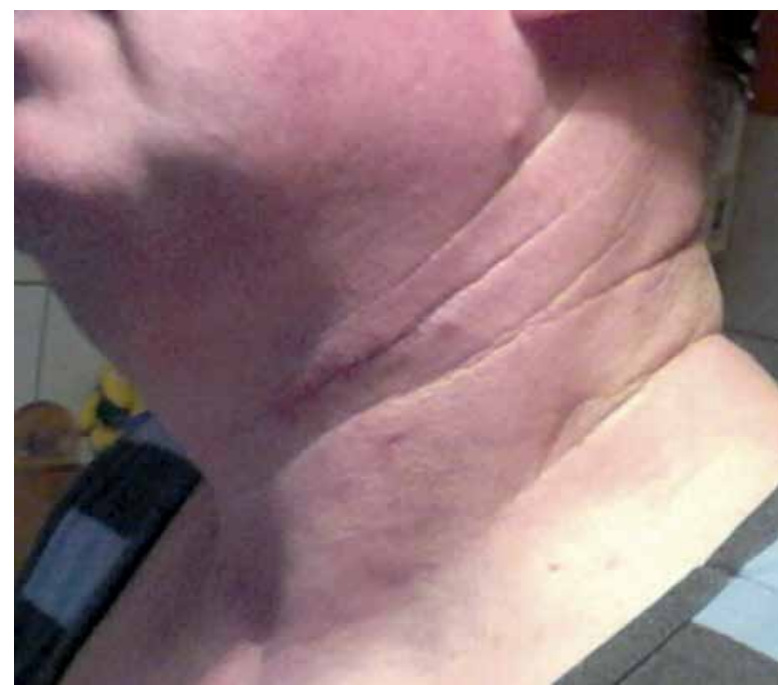

Photo 2. Example of a scar 2 months after surgery 
Table I. Patient characteristics and operative details

\begin{tabular}{|c|c|c|c|}
\hline \multirow[t]{2}{*}{ Epidemiologic details } & $\begin{array}{l}\text { Study group } \\
(n=100)\end{array}$ & $\begin{array}{l}\text { Control group } \\
\quad(n=100)\end{array}$ & \multirow[t]{2}{*}{$P$-value } \\
\hline & \multicolumn{2}{|c|}{ Number $=\%$} & \\
\hline Concern or not about cosmetics* & $30 / 70$ & $31 / 69$ & 0.514 \\
\hline Gender*, male/female & $61 / 39$ & $61 / 39$ & 0.546 \\
\hline Surgeon preferences*, for/against & $53 / 47$ & $47 / 53$ & 0.357 \\
\hline Shunt/no shunt & $11 / 89$ & $17 / 83$ & 0.195 \\
\hline \multicolumn{4}{|l|}{ CEA type: } \\
\hline Primary suture & 96 & 86 & 0.332 \\
\hline Patch plasty & 2 & 14 & 0.003 \\
\hline By eversion & 2 & 0 & 0.254 \\
\hline Side operated: left/right & $39 / 61$ & $59 / 41$ & 0.062 \\
\hline \multirow[t]{2}{*}{ Symptomatic/not symptomatic } & $69 / 31$ & $76 / 24$ & 0.369 \\
\hline & \multicolumn{3}{|c|}{ Mean \pm SD } \\
\hline Age [years] & $70.2 \pm 9.3$ & $68.7 \pm 8.4$ & 0.203 \\
\hline $\mathrm{BMI}\left[\mathrm{kg} / \mathrm{m}^{2}\right]$ & $27 . \pm 3.6$ & $25.7 \pm 3.8$ & 0.112 \\
\hline
\end{tabular}

\section{Skin wrinkle position}

Skin wrinkle distributions are shown in Table II. The mean distance between the access skin wrinkle and mandible ankle was $4.46 \pm 1.02 \mathrm{~cm}$ (range: $3-6 \mathrm{~cm}$ ). The mean distance between the carotid artery bifurcation and the mandible angle was $4.14 \pm 1.07 \mathrm{~cm}$ (range: $2-7 \mathrm{~cm}$ ). The mean number of visible skin wrinkles was $2.07 \pm 0.88$ (range: $0-4$ ). In 5 cases there were no visible skin wrinkles in the neutral neck position. However, after the patients bent their necks, they all showed a very clear location for future wrinkles (Langer's line).

Table II. Distance from mandibular angle to access skin wrinkle and carotid artery bifurcation

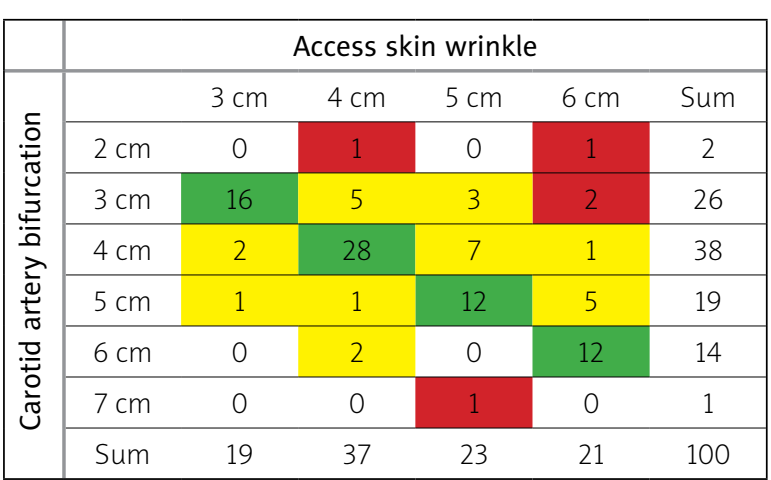

Range of distance between access skin crease and location of $C A B$ is: $0-1 \mathrm{~cm}$ in 68 cases (green), $1-2 \mathrm{~cm}$ in 27 cases (yellow) and $>2 \mathrm{~cm}$ in 5 cases (red) (100 cases - study group).

\section{Satisfaction and cosmetic effect}

Although the patients operated on expressed concern about the risk of stroke, $30 \%$ of them nonetheless stated that cosmetic effects were of importance. The POSAS score at the $2^{\text {nd }}$ and $12^{\text {th }}$ month after surgery is presented in Table III.

The superiority of the trans-wrinkle technique versus a conventional vertical technique was evident in the POSAS score. Moreover, $90 \%$ of the patients in the study group found their scar to be invisible after

Table III. Patient and Observer Scar Assessment Scale (POSAS) in relation to skin incision and time of follow-up

\begin{tabular}{|lccc|}
\hline POSAS Score & \multicolumn{2}{c|}{ Mean \pm SD } & P-value \\
\hline 2 months & $\begin{array}{c}\text { Study } \\
(n=100)\end{array}$ & $\begin{array}{c}\text { Control } \\
(n=100)\end{array}$ & \\
\hline Observer (out of 50) & $5.3 \pm 0.7$ & $6.7 \pm 1.9$ & 0.0001 \\
\hline Patient (out of 60) & $6.3 \pm 0.5$ & $7.6 \pm 1.6$ & 0.0001 \\
\hline Total (out of 110) & $11.4 \pm 1.0$ & $14.1 \pm 3.4$ & 0.0001 \\
\hline 12 months & $\begin{array}{c}\text { Study } \\
(n=98)\end{array}$ & $\begin{array}{c}\text { Control } \\
(n=98)\end{array}$ & \\
\hline Observer (out of 50) & $6.3 \pm 1.5$ & $6.8 \pm 2$ & 0.023 \\
\hline Patient (out of 60) & $7.3 \pm 1.4$ & $7.8 \pm 1.8$ & 0.019 \\
\hline Total (out of 110) & $13.5 \pm 2.8$ & $14.5 \pm 3.7$ & 0.039 \\
\hline
\end{tabular}


12 months (whereas in the control group, $25 \%$ made a similar statement).

\section{Medical results}

Results of the treatment were similar for both groups. The cumulative count of strokes and myocardial infarctions was $0.5 \%$ within 30 days, and 3.5\% after 1 year (with 5.5\% fatalities). Four patients died in follow-up (reason unknown) (Table IV).

\section{Discussion}

\section{Cosmetic effect}

Although the cosmetic effect is less important than the clinical result (stroke protection), there is still nonetheless room for less invasive carotid surgery. The need for minor invasive surgery is based on the fact that the scar is visible on the neck after CEA. However, carotid artery stenting (CAS) leaves no scar on the neck and is used for both atherosclerotic stenosis and trauma dissection of internal carotid stenosis [16]. There is still a place for CEA, especially within the mini-invasive approach, due to the yet unproven superiority of CAS over CEA. This means that the shorter the scar, the better it is, and the easier it is to hide it under folds of skin or skin wrinkles. This is a well-established method used at a variety of sites on a regular basis. However, worldwide, such a technique is undoubtedly less popular even with the available results of comparisons between oblique and transversal incisions [1-5, 17]. Furthermore, minimally invasive CEA has been suggested to be technically more difficult $[5,18]$. This is indeed the case if the surgeon operates through a $1-2 \mathrm{~cm}$ incision. For safety reasons the wound should be long enough to comfortably expose the carotid artery bifurcation. A transverse incision allows for easy access to the very highly located ICA bifurcation. Conversely, a lower location of ICA bifurcation might be more difficult in the case of just such an incision. Therefore, leading a reasonably long incision along the skin wrinkle appears to be the optimal choice in a transverse attempt. This method allows the skin creases to extend the incision (laterally) when necessary, without significant limitation, and the scar can be still hidden in the skin crease. Unfortunately, due to the fact that the comfort of the surgeon during surgery is of utmost importance, and to ensure patient safety, most vascular surgeons are not partic-
Table IV. Medical results

\begin{tabular}{|c|c|c|c|}
\hline Parameter & $\begin{array}{l}\text { Study } \\
\text { group } \\
(n=100)\end{array}$ & $\begin{array}{l}\text { Control } \\
\text { group } \\
(n=100)\end{array}$ & $P$-value \\
\hline \multicolumn{4}{|l|}{ Results up to 1 month: } \\
\hline Stroke & 0 & 1 & 0.502 \\
\hline $\begin{array}{l}\text { Myocardial } \\
\text { Infarction }\end{array}$ & 0 & 0 & 0.539 \\
\hline $\begin{array}{l}\text { Peripheral nerve } \\
\text { palsy }\end{array}$ & 22 & 11 & 0.055 \\
\hline Death & 0 & 0 & 0.539 \\
\hline \multicolumn{4}{|c|}{ Follow-up after 12 months: } \\
\hline $\begin{array}{l}\text { Stroke } \\
\text { (cumulative count) }\end{array}$ & 1 & 5 & 0.115 \\
\hline $\begin{array}{l}\text { Myocardial } \\
\text { infarction }\end{array}$ & 0 & 1 & 0.503 \\
\hline $\begin{array}{l}\text { Death } \\
\text { (cumulative count) }\end{array}$ & 2 & 2 & 0.689 \\
\hline $\begin{array}{l}\text { Persistent } \\
\text { peripheral nerve } \\
\text { palsy }\end{array}$ & 6 & 0 & 0.017 \\
\hline
\end{tabular}

ularly interested in cosmetic considerations. This limits not only all currently available comparisons between the two methods, but additionally those of patient preference, which have not been mentioned. Nevertheless, our study is the first randomized prospective study to compare a classic longitudinal incision and a transverse skin crease skin incision in CEA focused on cosmetic effects, as well as patient satisfaction. The choice of the POSAS scale probably allowed for more objective results and the reduction of subjective influences. POSAS is recommended by plastic surgeons and was successfully used in CEA scar assessment $[14,19,20]$. Our results are similar to the data already reported in the literature [17].

\section{Location of the skin incision}

Most surgeons (performing minimally invasive CEA) prefer to use ultrasound mapping of the bifurcation prior to the operation. This might be necessary if the intention is to use a very short skin incision $[1,2,5]$. The skin on the neck is very elastic, and therefore the risk of facing difficulties in case of a high $C A B$ is quite low. However, it is worth noting which skin crease is the best choice in terms of CEA. Our results suggest that it is preferable for an incision to be located about $4 \mathrm{~cm}$ below the mandible angle 
(with the patient's head in a sniffing position during surgery) (Table II). In $80 \%$ of cases, carotid artery bifurcation was located within a $2 \mathrm{~cm}$ range from the access skin wrinkle. In 2005 Asher published identical results within a group of 260 patients [1]. Moreover, if access is not comfortable enough, one can extend the skin incision laterally (without limit) to easily expose the bifurcation and still hide the scar in a crease. Moreover, stronger wound retraction might cause a nerve injury in such cases.

Despite the fact that the safety of both methods was not the topic of this study, a count of strokes was nonetheless conducted along with that of myocardial infarcts and deaths at 1 month and a year after, for safety reasons. The total count of all those endpoints (11 cases at 12-month follow-up) was $5.5 \%$ in both groups, which is lower than that reported in the NASCET trial $(9 \%)[6,21]$. There was a $0.5 \%$ risk of stroke peri-operatively, which is regarded as acceptable [6]. We do not know the reasons for the deaths (4 cases) in the follow-up period. Unfortunately, local nerve injury began to be a significant problem (Table IV). However, having no influence on patient satisfaction, the count of persistent neural palsy was higher in the study group. Symptoms were mainly hoarseness as a result of damage to the superior laryngeal nerve (4 cases) and significant sensory loss and numbing due to injury to the greater auricular nerve ( 2 cases). Although neural palsy occurs in $4 \%$ to $45 \%$ of cases (usually about 25\%), usually it is transient, in $80 \%$ of cases vanishing within 6 months [22-24]. Nevertheless, some of these nerve disorders have a long healing time, causing significant disability.

\section{Limitations}

The limitations of this study are related to a lack of fully objective tests that can compare satisfaction among patients regarding the techniques employed. Therefore, we chose the most popular POSAS scale (which takes into account not only patient/subjective opinion, but also professional/objective opinion). The second problem was surgeon preference (for/against surgical method) whilst completing the POSAS observer score and, with that in mind, an independent professional was involved in this study (a surgical nurse) to reduce this bias. Nevertheless, the most obvious limitation of this study was the impossibility of blinding the groups, since the scar position would always distinguish the study group from the control group.

\section{Clinical implications}

Patient safety is of utmost importance; therefore surgeon preferences as regards technique when performing CEA is a basic condition and should not have an impact on scar appearance. However, the satisfaction of the patient is significantly higher if the scar is hidden in the skin crease, especially during the early postoperative period. Moreover, a gentle surgical technique is needed to avoid local nerve injury whilst performing the trans-wrinkle approach. Uncomfortable anatomy could limit the use of the trans-wrinkle approach in cases when a stronger retraction is necessary to expose the CAB. Therefore ultrasound mapping of the carotid artery bifurcation might be useful prior to surgery.

\section{Conclusions}

Trans-wrinkle incision offers improved cosmetic results, can be safely performed in most cases, and can provide a comfortable approach during CEA.

\section{Conflict of interest}

The authors declare no conflict of interest.

\section{References}

1. Ascher E, Hingorani A, Marks N, et al. Mini skin incision for carotid endarterectomy (CEA): a new and safe alternative to the standard approach. J Vasc Surg 2005; 42: 1089-93.

2. De Troia A, Mosso F, Biasi L, et al. Carotid endarterectomy with mini-invasive access in locoregional anaesthesia. Acta Biomed l'Ateneo Parm 2008; 79: 123-7.

3. Dalsing MC. The training of carotid endarterectomy during an era of controversy. A personal experience. Am Surg 1990; 56: 476-86.

4. Mendes GAC, Zabramski JM, Elhadi AM, et al. Carotid endarterectomy: comparison of complications between transverse and longitudinal incision. Neurosurgery 2014; 75: 110-5.

5. Marcucci G, Antonelli R, Gabrielli R, et al. Short longitudinal versus transverse skin incision for carotid endarterectomy: Impact on cranial and cervical nerve injuries and esthetic outcome. J Cardiovasc Surg 2011; 52: 145-52.

6. Biller J, Feinberg WM, Castaldo JE, et al. Guidelines for carotid endarterectomy: a statement for healthcare professionals from a Special Writing Group of the Stroke Council, American Heart Association. Circulation 1998; 97: 501-9.

7. Sacco RL, Adams R, Albers G, et al. Guidelines for prevention of stroke in patients with ischemic stroke or transient ischemic attack: a statement for healthcare professionals from the American Heart Association/American Stroke Association Council on Stroke: co-sponsored by the Council on Cardiovascular Radi- 
ology and Intervention: the American Academy of Neurology affirms the value of this guideline. Stroke 2006; 37: 577-617.

8. Christianson D, Rizzo D. Provision of Karnofsky performance score (KPS) versus ECOG performance score (ECOG PS) to CIBMTR, Forms Man. Append. L-Karnofsky/Lansky Perform. Status 2009; 1-5.

9. White SJ, Freedman LS. Allocation of patients to treatment groups in a controlled clinical study. Br J Cancer 1978; 37: 849-57.

10. Kukowska A, Dziadziuszko R, Jassem J. Metody losowego przydziału leczenia w badaniach klinicznych. Onkologia 2005; 1 151-6.

11. Langer K. On the anatomy and physiology of the skin - II. Skin tension. Br J Plast Surg 1978; 31: 93-106.

12. AbuRahma AF, Mousa AY, Stone PA. Shunting during carotid endarterectomy. J Vasc Surg 2011; 54: 1502-10.

13. Lawrence PF, Alves JC, Jicha D, et al. Incidence, timing, and causes of cerebral ischemia during carotid endarterectomy with regional anesthesia. J Vasc Surg 1998; 27: 329-37.

14. Draaijers LJ, Tempelman FRH, Botman YM, et al. The patient and observer scar assessment scale: a reliable and feasible tool for scar evaluation. Plast Reconstr Surg 2004; 113: 1960-7.

15. Schulz KF, Altman DG, Moher D. CONSORT 2010 statement: updated guidelines for reporting parallel group randomized trials. Ann Intern Med 2010; 152: 726-32.

16. Wachal K, Koczewski P, Gabriel M, et al. Isolated internal carotid artery dissection in a long-distance runner. Videosurgery Miniinv 2016; 11: 304-8.

17. Deck M, Kopriva D. Patient and observer scar assessment scores favour the late appearance of a transverse cervical incision over a vertical incision in patients undergoing carotid endarterectomy for stroke risk reduction. Can I Surg 2015; 58: 245-9.

18. Sajid MS, Vijaynagar B, Singh P, et al. Literature review of cranial nerve injuries during carotid endarterectomy. Acta Chir Belg 2007; 107: 25-8.

19. Stavrou D, Haik J, Weissman O, et al. Patient and observer scar assessment scale: how good is it? I Wound Care 2009; 18: 171-6.

20. Van Der Wal MBA, Tuinebreijer WE, Bloemen MCT, et al. Rasch analysis of the patient and o Observer Scar Assessment Scale (POSAS) in burn scars. Qual Life Res 2012; 21: 13-23.

21. Ferguson GG, Eliasziw M, Barr HW, et al. The North American Symptomatic Carotid Endarterectomy Trial: surgical results in 1415 patients. Stroke 1999; 30: 1751-8.

22. Hertzer NR, Feldman BJ, Beven EG, et al. A prospective study of the incidence of injury to the cranial nerves during carotid endarterectomy. Surg Gynecol Obstet 1980; 151: 781-4.

23. Evans WE, Mendelowitz DS, Liapis C, et al. Motor speech deficit following carotid endarterectomy. Ann Surg 1982; 196: 461-4.

24. AbuRahma AF, Choueiri MA. Cranial and cervical nerve injuries after repeat carotid endarterectomy. J Vasc Surg 2000; 32: 649-54.

Received: 8.06.2017, accepted: 2.09.2017. 
Appendix 1. POSAS Scale

Observer Scar Assessment Scale

$\begin{array}{llllllllllll}\text { Normal skin } & 1 & 2 & 3 & 4 & 5 & 6 & 7 & 8 & 9 & 10 & \text { Worst scar imaginable }\end{array}$

Vascularization $\bigcirc \quad 0 \quad 0 \quad 0 \quad 0 \quad 0 \quad 00000$

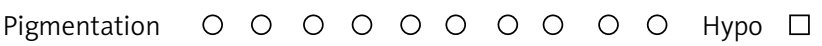

Mix $\square$

Thickness $0 \quad 0 \quad 0 \quad 0 \quad 0 \quad 0 \quad 0000$

Relief $\bigcirc \circ \bigcirc 0000000$

Pliability $\bigcirc \circ 000000000$

Total score Observer Scar Scale:

\begin{tabular}{|c|c|c|c|c|c|c|c|c|c|c|c|}
\hline \multicolumn{12}{|l|}{ Patient Scar Assessment Scale } \\
\hline No, no complaints & 1 & 2 & 3 & 4 & 5 & 6 & 7 & 8 & 9 & 10 & Yes, worst imaginable \\
\hline Is the scar painful? & O & O & $\mathrm{O}$ & O & O & O & O & O & $\mathrm{O}$ & $\mathrm{O}$ & \\
\hline Is the scar itching? & O & O & 0 & 0 & 0 & O & O & O & O & O & \\
\hline No, as normal skin & 1 & 2 & 3 & 4 & 5 & 6 & 7 & 8 & 9 & 10 & Yes, very different \\
\hline Is the color of the scar different? & O & O & O & 0 & O & ○ & O & O & O & O & \\
\hline Is the scar more stiff.? & O & O & O & 0 & O & O & O & O & O & O & \\
\hline Is the thickness of the scar different? & O & O & O & 0 & O & O & O & O & $\mathrm{O}$ & O & \\
\hline Is the scar irregular? & 0 & 0 & 0 & 0 & 0 & 0 & 0 & 0 & 0 & 0 & \\
\hline
\end{tabular}

